\title{
Advertising and Consumer Choice of Telecom- munication Services in Nigeria
}

- David Oladipo Olalekan, Abina Musiliu Babatunde, Oyeniran Wasiu Ishola

\begin{abstract}
This study examines the critical influence of advertising on consumer choice of telecommunication services in Nigeria. The advertisement played a key role in providing the consumers with product information. The study investigates the effect of marketing medium of telecommunication as a proxy for advertisement on preference of telecommunication services as a proxy for consumer choice in Nigeria. The Binary Logit Model (BLM) and descriptive analytical frameworks are used to evaluate the statistical importance of advertisement, quality of services, income of the consumer, product's self and related service charges for a consumer choice of telecommunication services through Wald test. The findings show that product's self service charge and service quality are statistically significant for a consumer choice of telecommunication services in Nigeria at 1 percent significance level. And, related product's service is statistically significant for a consumer choice of telecommunication services in Nigeria at 5 percent significance level. While advertisement and income of the consumer are statistically significant for a consumer choice of telecommunication services in Nigeria at 10 percent. The study concludes that advertisement is important for the choice of telecommunication services in Nigeria but having less impact. And, product's self service charge and service quality are hugely significant for the choice of telecommunication services in Nigeria. Therefore, the sector of telecommunications needs more investment in advertisement so as to have telecommunications' products information spread in order to stimulate the increase in demand for telecommunication services in Nigeria.
\end{abstract}

Keywords: Advertising, Consumer choice and telecommunication services in Nigeria

JEL Classification: M37, D91, L96

\section{INTRODUCTION}

\section{Background}

Varieties of products are constantly on offer for consumers' attention and, ultimately, for consumption. To publicize the brands on offer, organisations employ the use of advertising to create awareness, educate on distinct features and benefits, and facilitate the creation of positive brand images (Ehrenberg, Barnard, Kennedy \& Bloom, 2002; Shimp, 2007). Advertising aids decision making by keeping the company's brand more salient. Effective advertising influences customers to try advertised products and services (Shimp, 2007). Selecting from the brands advertised demands that consumers constantly make decisions about the choice of products they patronize, purchase and consume. During the search for information about a product or service, the function of advertising is to inform and persuade the undecided consumer. Advertising effectiveness is thus associated with the way the consumer subsequently processes the content of the advertisement (Ducoffe, 1996). 
Tracing the impact of advertising on consumer choice offers two substantial advantages. First, it allows access to a large selection of naturally occurring stimuli. Second, it offers a natural observable consequence of successful persuasion, namely, the choice of advertised product (Russo \& Chaxel, 2010). Although, advertising effectiveness is measured through the resulting attitude towards the product advertised, choice is used in this study to assess the primary role advertising plays in consumer's decision among competing range of options.

That advertising can influence product purchase is well established (e.g. Ailawady \& Neslin, 1998; Tellis, Chandy \& Thaivanich, 2000). Empirical studies on how advertising works are also numerous (e.g. Hoch \& Ha, 1986). Much literature examines how consumers process information about available offers on the market and make choices from among these options in relevant choice situations (Ehrenberg et al., 2002), and, thereby, increase the likelihood of purchasing brands that otherwise might not be chosen (Machleit, Allen \& Madden, 1993). However, to our knowledge, there is no existing study on the relationship and interaction of advertising and consumer choice in the context of telecommunication services in Nigeria.

\section{Research Problems}

Past studies on consumer choice have focused on several factors that influence decision making. The studies have examined the influence of price presentation order on consumer choice(Suk, Lee, \& Lichtenstein, 2012), television advertising and branding effect on eating behavior and preferences (Boyland \& Halford, 2012), the influence of online product recommendations on consumers' online choices (Senecala \& Nantel, 2004), sensory aspect of consumer choices (Resurreccion, 2003), and the influence of structural alignment on choices among a set of options such as comparative advertising (Markman, \& Loewenstein, 2010).

The relationships between product information and consumer behavior in terms of perceptions of various telecommunication services and how these perceptions are associated with final purchase decision making have not previously been studied. For those reasons, the present study was designed to examine the influence of advertising on consumer choice with particular focus on telecommunications services in Nigeria.

\section{Objectives of the Study}

1. to identify the determinants of the consumers' choice of telecommunication services in Nigeria

2. to examine if advertising influences the choice of telecommunications services patronised by consumers.

3. to investigate if advertising motivates consumers to consider purchase of a particular telecommunications brand.

\section{LITERATURE REVIEW}

\section{Conceptual}

Advertising is paid-for communication to more than one person, intended to inform or change behaviour (Broadbent, 2001). It is a mediated form of communication from an identifiable 
source, designed to persuade the receiver to take some action, now or in the future (Richards \& Curran, 2002). Advertising is a key element of the promotional activity which has become the undisputed spokesman of modern marketing which is characterised by centralized and mass production, differentiated and branded products, widely dispersed and sophisticated consumers (Onyenyili-Onuorah, 2005). As espoused by Keller (2008), it is a powerful means of creating strong, favourable, and unique brand associations and eliciting positive judgements and feelings. In a free society, advertising is an important tool in the competition which is the invisible hand guiding production (McDonald, 1992). As products are produced and introduced into the market, advertising helps get the new product off the ground by giving more people more "complete information" thereby stimulating primary demand for the entire product class. Furthermore, it has the potential to influence selective demand for a particular brand (Arens, 2002).Consequently, the effect on consumer demand sets off a chain reaction and, thus, affects consumer choice. The freedom to advertise promotes the existence of more sellers, and that gives consumers wider choices (Arens, 2002).

Choice presupposes the existence of alternative courses of action. It also implies access or ability to follow any of the available courses of action without hindrance. Quality of individual choices is usually influenced by information about the available options. The extent and quality of choice which consumers exercise in the economy will be greatly affected by the scope of advertising in operation in that economy. Advertising messages, like all marketing communication messages, are directed toward influencing consumers' brand-related beliefs, attitudes, emotional reactions, and choices (Shimp, 2007). Advertising enhance the extent and quality of choices that consumers make by providing regular and quality information on available products and their uses. However, in some respects, it tends to limit the scope of consumer choice especially in situations where only few of several alternative products are advertised and given prominence over other alternatives (Onyenyili-Onuorah, 2005).

\section{Theoretical Framework}

A number of models have been developed to describe the consumer decision making process and consumer behaviour. The study of consumer behaviour is generally divided into two different approaches: the consumer processing model (CPM) and the hedonic and experiential model (HEM). Consumer-processing model (CPM) and Hedonic experiential model (HEM) explains how consumers make decisions about their choices. From the consumer-processing perspective (CPM), information processing and choice are seen as rational, cognitive, systematic, and reasoned (Leigh \& Martin, 1990).This in tandem with the views of traditional economist who postulated that demand is based on product own price, relative price, income of the consumer and taste (Marshall, 1920).The consumer is constantly bombarded with information which is potentially relevant for making choices. The consumer's reactions to that information, how that information is interpreted, and how it is combined or integrated with other information may have crucial impacts on choice (Bettman, 1979). With the consumer processing model, consumer behaviour is highly cognitive, rational, systematic, and reasoned. Hence, advertisement decisions must be developed and integrated into how consumers make choices. 
The hedonic, experiential perspective (HEM), on the other hand, views consumer processing of communication messages and behaviour as driven by emotions in pursuit of fun, fantasies, and feelings (Hirschman \& Holbrook, 1982).Advancing the HEM, Shimp (2007) adds that the HEM viewpoint recognizes that people often consume products for the sheer fun of it or in the pursuit of amusement, fantasies, or having pleasurable feelings.

Dawson, Bloch, and Ridgway (1990) contend that consumers are motivated by three broad categories of needs that are (a) utilitarian or product-related, (b) hedonic or recreational, and (c) a combination of both utilitarian and hedonic. In trying to satisfy these needs, consumers process advertising information and ultimately use this information to choose from among the alternatives available in the marketplace.

Many empirically important economic decisions involve choice among discrete alternatives (McFadden, 1978). The Classical economist (Marshal, 1920) opined that choice of consumption of any commodity (product) is solely determined by the price of the product, price of related products, income of the consumer and taste of the consumer, though, there are other factors that determine consumer's choice. He assumed further that there is existence of perfect flow of information (advertisement) in the market that equip the consumers in order to make appropriate decisions and choices.

\section{Empirical Studies}

Much research of advertising has been conducted into consumer choice (Markman \& Loewenstein, 2010; DiClemente \& Hantula, 2003). This study is particularly appropriate given the constant and repetitive advertising of telecommunications services. The question arises as to the effect of this promotional activity on consumer choice of telecommunication services in Nigeria.

We found only one study that examined the influence of a persuasive message (advertising) effects on consumer choice (Russo \& Chaxel, 2010).The study employed an experimental design consisting of 203 participants divided and placed under five conditions; two uncontrolled and three controlled; in verifying the ability of a specific, observable process to explain the influence of a persuasive message on choice. The study indicated that although people are aware of advertising's direct effect on their choice, they are not aware of its indirect effect through biased evaluation of the product information.

In another study, Boyland and Halford (2012) examined the question of whether television advertising and branding had an effect on choice of food. However, the study was not limited to choice only; it also examined effects on eating behaviour. From their research, they concluded that the impact of advertising and branding on children is readily demonstrated by their brand recognition, and its influence on food choice.

\section{METHODOLOGY AND MODEL}

Rationale for this study's model lies in the consumer behaviour theory as emphasised in literatures (Marshall, 1920; Russo \& Chaxel, 2010; Boyland \& Halford 2012). Thus, the study employed a Binary Logit Model (BLM) method of estimation due to categorical response nature of research target variable that telecommunication consumers in Nigeria preferred other network 
provider to be the market leader to otherwise (MTN) i.e. If Preferred, 1 and 0 if otherwise. The consumer choice of telecommunication services of the respondents is captured by preference of telecommunication services provider's dominance.

Thus, the model is stated as

$\mathrm{P} r_{i}=E\left(T c h_{i}=1 / M_{i}\right)=\beta_{0}+\beta_{i} M_{i}+U_{i}$

Where Mi is the vector of telecommunication market information spread indicators of Telecommunication operators and $\mathrm{T}_{\mathrm{ch}}=1$ means customers of telecommunication services preferred other network provider to be the market dominant with respect to MTN and Zero (0) if otherwise. Further, $\mathrm{M}_{\mathrm{i}}=\mathrm{f}\left(\mathrm{Ic}_{\mathrm{i}}, \mathrm{Adv}_{\mathrm{i}}, \mathrm{Pch}_{\mathrm{i}}, \mathrm{Ca}_{\mathrm{i}}, \mathrm{Qch}_{\mathrm{i}}\right)$ and can be Mathematically stated as

$M_{i}=\Psi_{0}+\Psi_{1} I c_{i}+\Psi_{2} A d v_{i}+\Psi_{3} P c h_{i}+\Psi_{4} C a_{i}+\Psi_{5} Q c h_{i}+e_{i}$

But now let consider the following representation of preference of telecommunication services by network providers in Nigeria from (3.1)

$\operatorname{Pr}_{i}=E\left(T c h_{i}=1 / M_{i}\right)=\frac{1}{1+e^{-(\beta 0+\beta i M i+U i)}}$

Assume $Z_{i}=\beta_{o}+\beta_{i} M_{i}+U_{i}$

Thus; $\operatorname{Pr}_{i}=\frac{1}{1+e^{-Z i}}=\frac{e Z}{1+e^{Z i}}$

Equation 3.4 represents the cumulative logistic distribution function, where $\operatorname{Pr}_{\mathrm{i}}$ ranges from 0 and 1 and $Z_{\mathrm{i}}$ ranges from $-\infty$ to $+\infty$.

If $\mathrm{Pr}_{\mathrm{i}}$, is the probability of customers of telecommunication services preferred other network provider to be the market dominant with respect to MTN in Nigeria then $\left(1-\mathrm{Pr}_{\mathrm{i}}\right)$, is the probability of preference of MTN as market dominant.

Therefore,

$$
\begin{aligned}
& \left(1-P r_{i}\right)=1-\left[\frac{e Z i}{1+e^{Z i}}\right] \\
& 1-P r_{i}=\frac{1}{1+e^{Z i}}
\end{aligned}
$$

The odd ratio of customers of telecommunication services preferred other network provider to be the market dominant with respect to MTN in Nigeria is (3.4) divided by (3.6)

$$
\begin{aligned}
& \frac{P r_{i}}{1-P r_{i}}=\frac{e^{Z i}}{1+e^{Z i}} / \frac{1}{1+e^{Z i}} \\
& \frac{P r_{i}}{I-P r_{i}}=e^{Z i}
\end{aligned}
$$


Taking the natural log of (3.8) to obtain the Liner Probability Model (LPM)

$$
\begin{aligned}
& L_{i}=\operatorname{In}\left(\frac{P r_{i}}{1-P r_{i}}\right)=\operatorname{In}\left(e^{Z_{i}}\right) \\
& L_{i}=\operatorname{In}\left(\frac{P r_{i}}{1-P r_{i}}\right)=Z_{i} \\
& L_{i}=Z_{i}=\beta_{o}+\beta_{i} M_{i}+U_{i}
\end{aligned}
$$

Substitute (3.2) in (3.9)

$$
\begin{aligned}
& M_{i}=\Psi_{0}+\Psi_{1} I c_{i}+\Psi_{2} A d v_{i}+\Psi_{3} P c b_{i}+\Psi_{4} C a_{i}+\Psi_{5} Q c h_{i}+e_{i} \\
& L_{i}=\beta_{0}+\beta_{1}\left(\Psi_{0}+\Psi_{1} I c_{i}+\Psi_{2} A d v_{i}+\Psi_{3} P c b_{i}+\Psi_{4} C a_{i}+\Psi_{5} Q c b_{i}+e_{i}\right)+U_{i} \\
& L_{i}=\beta_{0}+\beta_{1} \Psi_{0}+\beta_{1} \Psi_{1} I c_{i}+\beta_{1} \Psi_{2} A d v_{i}+\beta_{1} \Psi_{3} P c b_{i}+\beta_{1} \Psi_{4} C a_{i}+\beta_{1} \Psi_{5} Q_{c} h_{i}+\beta_{1} e_{i}+U_{i} \\
& \text { Let } \Phi_{0}=\beta_{0}+\beta_{1} \Psi_{0}, \Phi_{1}=\beta_{1} \Psi_{1}, \Phi_{2}=\beta_{1} \Psi_{2}, \Phi_{3}=\beta_{1} \Psi_{3}, \Phi_{4}=\beta_{1} \Psi_{4}, \Phi_{5}=\beta_{1} \Psi_{5} \text { and } \varepsilon=\beta_{1} e_{i}+U
\end{aligned}
$$

Therefore,

$$
L_{i}=\Phi_{0}+\Phi_{1} I c_{i}+\Phi_{2} A d v_{i}+\Phi_{3} P c h_{i}+\Phi_{4} C a_{i}+\Phi_{5} Q c h_{i}+\varepsilon_{i}
$$

Where;

$T c h=$ Choice of Telecommunication services in Nigeria (Taking MTN as reference and most preferred)

$I c=$ Income of the customers

$A d v=$ Medium of advertisement

$P c h=$ Cost of consuming preferred Telecommunication Network services

$C a=$ Cost of consuming competing Telecommunication Network services

Qch $=$ Service Quality

The equation (3.11) is the Binary Logit Model (BLM) that estimates the Consumers' Choice of Telecommunication Services in Nigeria. The maximum likelihood (ML) technique aid estimation techniques in this study since ordinary least square (OLS) technique cannot be used to estimate data at micro level i.e. discrete data.

\section{Assumptions of the Model}

1. Consumers are rational in service purchase

2. There is even access to market information

3. Telecommunication services are normal products

4. There are substitutes to the preferred network

\section{Research Hypothesis}

$\mathrm{H}_{0}$ : Advertising does not have impact on consumers' choice of telecommunication services in Nigeria

$\mathrm{H}_{1}$ : Advertising has impact on consumers' choice of telecommunication services in Nigeria 
Tab. 3.1 - Summary of Dataset. Source: Authors, 2015.

\begin{tabular}{|c|c|c|c|c|}
\hline Variable & $\begin{array}{l}\text { Variable } \\
\text { Definition }\end{array}$ & $\begin{array}{l}\text { Variables' Proxy in } \\
\text { the Questionnaire }\end{array}$ & Code of Categorical Set & $\begin{array}{l}\text { Source } \\
\text { of Data }\end{array}$ \\
\hline Tch & $\begin{array}{l}\text { Choice of } \\
\text { Telecommunica- } \\
\text { tion services in } \\
\text { Nigeria (Taking } \\
\text { MTN as refer- } \\
\text { ence and most } \\
\text { preferred) }\end{array}$ & $\begin{array}{l}\text { MTN Network be- } \\
\text { ing the Market leader } \\
\text { in the Telecom- } \\
\text { munication sector } \\
\text { in Nigeria, would } \\
\text { you prefer another } \\
\text { Network to be the } \\
\text { Market leader? }\end{array}$ & $\begin{array}{l}0=\mathrm{No} \\
1=\mathrm{Yes}\end{array}$ & Survey \\
\hline Ic & $\begin{array}{l}\text { Income of the } \\
\text { customers }\end{array}$ & $\begin{array}{l}\text { Average Monthly } \\
\text { Income }\end{array}$ & $\begin{array}{l}1=\text { Less than N18,000 } \\
2=\text { N18,000 }- \text { N50,000 } \\
3=\text { More than N50,000 }\end{array}$ & Survey \\
\hline $\mathrm{Adv}$ & $\begin{array}{l}\text { Medium of } \\
\text { advertisement }\end{array}$ & $\begin{array}{l}\text { Main medium of ad- } \\
\text { vertisement for your } \\
\text { Telephone Network? }\end{array}$ & $\begin{array}{l}1=\text { Television } \\
2=\text { Radio } \\
3=\text { Newspapers/Journals } \\
4=\text { Billboards/Handbills } \\
5=\text { Other }\end{array}$ & Survey \\
\hline Pch & $\begin{array}{l}\text { Cost of consum- } \\
\text { ing preferred } \\
\text { Telecommunica- } \\
\text { tion Network } \\
\text { services }\end{array}$ & $\begin{array}{l}\text { How would you } \\
\text { describe the service } \\
\text { charge of your } \\
\text { Telephone Network } \\
\text { provider? }\end{array}$ & $\begin{array}{l}1=\text { Low } \\
2=\text { Moderate } \\
3=\text { High }\end{array}$ & Survey \\
\hline $\mathrm{Ca}$ & $\begin{array}{l}\text { Cost of consum- } \\
\text { ing competing } \\
\text { Telecommunica- } \\
\text { tion Network } \\
\text { services }\end{array}$ & $\begin{array}{l}\text { If provided with bet- } \\
\text { ter services by other } \\
\text { Network providers, } \\
\text { would you switch? }\end{array}$ & $\begin{array}{l}1=\mathrm{No} \\
2=\mathrm{Yes}\end{array}$ & Survey \\
\hline Qch & Service Quality & $\begin{array}{l}\text { How would you rate } \\
\text { service quality of } \\
\text { your Telephone Net- } \\
\text { work provider? }\end{array}$ & $\begin{array}{l}1=\text { Poor } \\
2=\text { Fair } \\
3=\text { Good } \\
4=\text { Excellent }\end{array}$ & Survey \\
\hline
\end{tabular}


Tab. 3.2 - A Priori Expectation of the Explanatory Variables. Source: Authors, 2015.

\begin{tabular}{|l|l|l|}
\hline Variable & Variable Definition & Expected sign \\
\hline Ic & Income of the customers & Positive $(+)$ \\
\hline Adv & Medium of advertisement & Positive $(+)$ \\
\hline Pch & $\begin{array}{l}\text { Cost of consuming preferred Telecom- } \\
\text { munication Network services }\end{array}$ & Negative $(-)$ \\
\hline Ca & $\begin{array}{l}\text { Cost of consuming competing Telecom- } \\
\text { munication Network services }\end{array}$ & Positive $(+)$ \\
\hline Qch & Service Quality & Positive $(+)$ \\
\hline
\end{tabular}

\section{Sample Survey and Scope}

The study was conducted in Nigeria and the data used were gathered from the six (6) geo-political zones that made up Nigeria i.e. South-west, South-south, South-east, North-central, Northwest and North-east. This research work was carried out between September, 2014 and April, 2015 which is eight (8) months. The study employed structured questionnaire to elicit required information from the subscribers of Telecommunications services providers in Nigeria through online medium i.e. online questionnaire form powered by Google forms. The study administered 3,600 questionnaires which comprises of 600 questionnaires to each geo-political zone in Nigeria but 3,458 questionnaires were returned. The response rate is 96 percent which is a fair representation of the total number of administered questionnaires.

\section{Methods of Estimation}

From the data collected through questionnaire administration to the customers of the telecommunication services providers in Nigeria, the frequency count, mean and simple percentage are used to classify the consumers of telecommunication services in Nigeria. Binary Logit analysis through maximum likelihood estimation technique was used for the model. Analysis of variance (ANOVA) is validated through chi square $\left(\chi^{2}\right)$ of the logit equation and Wald tests were conducted to assess whether consumers with different socio-demographic characteristics have different perceptions on the telecommunications market dominance preference.

\section{DATAAND RESULTS}

\section{Telecommunication Operators' Market share in Nigeria}

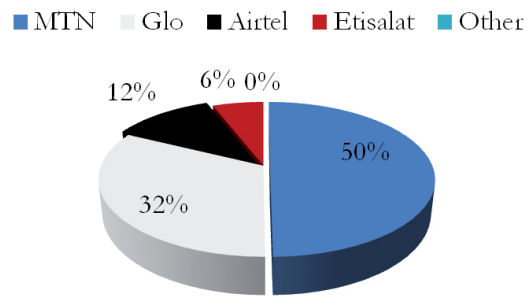

Fig. 4.1 - Source: Author, 2015 
Figure 4.1 shows the extent of market penetration of the telecommunication services provider in Nigeria and this captured through most used telecommunication network by the respondents. The result shows that 50 percent of the respondents patronise MTN, 32 percent are use Glo network often, 12 percent prefer Airtel while only 6 percent of the respondents subscribe to the services of Etisalat. From figure 4.1, it is glaring that MTN dominates the telecommunication market in Nigeria with control of half of the total market share.

\section{Empirical Results}

Tab. 4.1 - Binary Logit Estimates for Consumers' Choice of Telecommunication Services in Nigeria. Source: Researchers' Computation, 2015.

\begin{tabular}{|c|c|c|c|c|}
\hline \multirow{2}{*}{ Variable } & Coefficient & Wald ratio & $\mathrm{p}$ - value & Odds ratio \\
\hline Intercept & -2.216 & 16.196 & 0.000 & 0.109 \\
\hline $\mathrm{I}_{\mathrm{c}}$ & 0.225 & $2.753^{*}$ & 0.097 & 1.253 \\
\hline $\mathrm{A}_{\mathrm{dv}}$ & -0.344 & $3.717^{*}$ & 0.054 & 0.709 \\
\hline $\mathrm{P}_{\mathrm{ch}}$ & 1.262 & $33.056^{* * *}$ & 0.000 & 3.534 \\
\hline $\mathrm{C}_{\mathrm{a}}$ & -0.514 & $3.981^{* *}$ & 0.046 & 0.598 \\
\hline $\mathrm{Q}_{\mathrm{ch}}$ & 0.811 & $13.275^{* * *}$ & 0.000 & 2.249 \\
\hline $\mathrm{N}=3458$ & Nagelkerke $\mathrm{R}^{2}=0.907$ & $\chi^{2}=3943.093(0.000)$ & \\
\hline
\end{tabular}

Note: “***”, “**”, and “*” indicated at least significance at $1 \%, 5 \%$ and $10 \%$ level.

Reference Category: Yes

\section{Discussion of the Empirical Results}

The Binary logit estimate for Consumers' Choice of Telecommunication Services in Nigeria is presented in table 4.1. The probability effects of the explanatory variables \{Income of the customers (Ic), Medium of advertisement (Adv), Cost of consuming preferred Telecommunication Network (Pch), Cost of consuming competing Telecommunication Network providers (Ca) and Service Quality $(\mathrm{Qch})\}$ are determined by maximum likelihood techniques and satisfy the Independence of Irrelevant Alternatives (IIA) assumptions.

The empirical results show that Income of the customers (Ic) is directly related to Consumers' choice of Telecommunication services in Nigeria and it this agrees with the economic a priori expectation. The Medium of advertisement (Adv) is inversely associated with the Consumers' choice of Telecommunication services in Nigeria but this negates the economic a priori expectation. The finding shows that the Cost of consuming preferred Telecommunication Network (Pch) is directly related to the Consumers' choice of Telecommunication services in Nigeria which disagree with the economic a priori expectation. The Cost of consuming competing Telecommunication Network providers (Ca) is negatively related to Consumers' choice of Telecommunication services in Nigeria and this conform with the economic a priori expectation. The Service Quality (Qch) is directly associated with the Consumers' choice of Telecommunication services in Nigeria and this follow the economic a priori expectation. 
The parameter estimates of the regressors (Income of the customers (Ic), Medium of advertisement (Adv), Cost of consuming preferred Telecommunication Network (Pch), Cost of consuming competing Telecommunication Network providers (Ca) and Service Quality (Qch)\} show the elasticity of Consumers' choice of 'Telecommunication services in Nigeria. The results depict that Income of the customers causes 22.5 percent increase in the Consumers' choice of Telecommunication services in Nigeria. But, medium of advertisement causes 34.4 percent drop in the Consumers' choice of Telecommunication services in Nigeria. While, cost of consuming preferred Telecommunication Network causes 126.2 percent rise in the Consumers' choice of Telecommunication services in Nigeria. The cost of consuming competing Telecommunication Network providers causes 51.4 percent drop in the Consumers' choice of 'Telecommunication services in Nigeria. And, Service Quality increases the Consumers' choice of Telecommunication services in Nigeria by 81.1 percent.

The Wald ratio test measures the individual regressors \{ Income of the customers (Ic), Medium of advertisement (Adv), Cost of consuming preferred Telecommunication Network (Pch), Cost of consuming competing Telecommunication Network providers (Ca) and Service Quality (Qch)\} significance to theregressand (Choice of Telecommunication services in Nigeria). The test reveals that Cost of consuming preferred Telecommunication Network and Service Quality are statistically significant to the Consumers' choice of Telecommunication services in Nigeria at 1 percent significance level. The cost of consuming competing Telecommunication Network providers is statistically significant to the Consumers' choice of 'Telecommunication services in Nigeria at 5 percent but Income of the customers and Medium of advertisement are statistically significant to the Consumers' choice of Telecommunication services in Nigeria at 10 percent significance level. This implies that cost of consuming preferred Telecommunication Network and Service Quality exert strong pressures on the Consumers' choice of 'Telecommunication services in Nigeria while the cost of consuming competing Telecommunication Network providers exert moderate pressures on the Consumers' choice of Telecommunication services in Nigeria. But, Income of the customers and Medium of advertisement exert fair pressures on the Choice of Telecommunication services in Nigeria.

The overall significance test of the regressors \{income of the customers (Ic), medium of advertisement (Adv), cost of consuming preferred Telecommunication Network (Pch), cost of consuming competing Telecommunication Network providers (Ca) and service quality $(\mathrm{Qch})\}$ is ascertained through the chi square test $\left(\chi^{2}\right)$. The test reveals that when all the parameter estimates of the explanatory variables are jointly measured in term of the statistical importance to the regressand, the regressors are statistically significant to the Consumers' choice of Telecommunication services in Nigeria at 1 percent significance level due to its p-value less than 0.01 . This result validates the alternative hypothesis $\left(\mathrm{H}_{1}\right)$ of the study that advertising has impact on consumers' choice of telecommunication services in Nigeria.

The coefficient of determination tests the extent of variations in the consumers' choice of telecommunication services in Nigeria caused by the deterministic components \{Income of the customers, Medium of advertisement, Cost of consuming preferred Telecommunication Network, Cost of consuming competing Telecommunication Network providers and Service Quality $\}$ and the stochastic component of the model. This is evaluated through the "Nagelkerke R 
Square" which shows a strong deterministic value of 0.907 . This implies that about 90.7 percent variations in consumers' choice of telecommunication services in Nigeria are caused by Income of the customers, medium of advertisement, cost of consuming preferred Telecommunication Network, cost of consuming competing telecommunication network providers and service quality. But, the stochastic term caused about 9.3 percent variations in the consumers' choice of telecommunication services in Nigeria.

The Odd ratio measures the probability that Telecommunication consumers in Nigeria prefer other network provider to be the market leader to otherwise (MTN). The probability that consumers prefer other networks with respect to advertisement and market information is 0.71 (approximately 1) to 1 in Nigeria. This implies that 1 out of 100 consumers have privilege of influenced by advertisement of telecommunication services in Nigeria.

\section{CONCLUSION AND RECOMMENDATIONS}

Information played pivotal role in business progress in which Nigeria is not an exceptional. The rate of Information spread is key to business efficiency from the perception of product production, exchange and consumption. The advent of telecommunications Liberalization fading out direct business contact that have dominated business transactions from the era of Nigeria post-independence. The spillover effect of Telecommunication service cannot be neglected in the boom of gross output experienced in Nigeria from 2000 to date. The advertising of telecommunications services take different dimensions which have impacted greatly on the demand for the telecommunications products, ranging from Telephone calls, SMS, internet services, etc in Nigeria. Therefore, Marketing of telecommunications products have less significant impact on choice of telecommunications demand in Nigeria. While, product's self service charge and service quality exert high pressure on consumer choice of telecommunications services in Nigeria. Thus, this study recommends that;

1. Telecommunications operator should invest meaningfully on advertisement as to make their products well known to the consumers. Healthy advertisement policy should be put in place for adequate marketing that will equip the consumer with needed market information of the products and services of Telecommunications operators.

2. Service charge by telecommunication operators played a key role in the choice of telecommunication services. More Liberalization in the telecommunication industry market will stimulate lower prices of services and increase the demand for telecommunications products.

3. Quality of service is a major determinant of choice of telecommunications services in Nigeria and the better the quality of services, the higher the level of patronage of their products. The regulatory body must ensure that Telecommunications operator provide quality services that conform with international best practice.

4. Sufficient income for the consumer should be supported by the government, so as to raise the standard of living through increase in individual personal expenditure that will influence consumers' choice of telecommunication services. 


\section{References}

1. Ailwady, K. L., \& Neslin, S. A. (1998). The effect of promotion on consumption: Buying more and consuming it faster. Journal of Marketing Research, 35(3), 390-398. doi:10.2307/3152036

2. Arens, W. F. (2002). Contemporary advertising (Vol. 8.). New York: McGraw-Hill/Irwin.

3. Bettman, J. B. (1979). An information processing theory of consumer choice. Reading, Mass: Addison-Wesley.

4. Boyland, E. J., \& Halford, J. C. G. (2012). Television advertising and branding: Effects on eating behavior and preferences in children. Appetite, retrieved from www.http://dx.doi. org/10.1016/j.appet.2012.01.032

5. Broadbent, S. (2001). Advertising. In M. J. Baker (ed.). The IEBM encyclopedia of marketing. London: International Thomson Business Press.

6. Dawson, S., Bloch, P. H., \& Ridway, N. M. (1990). Shopping motives, emotional states, and retail outcomes. Journal of Retailing, 66, 408-427.

7. DiClemente, D. A., \& Hantula, D. F. (2003). Applied behavioral economics and consumer choice. Journal of Economic Psychology, 24, 589-602. doi:10.1016/s0167-4870(03)00003-5

8. Ducoffe R. H. (1996). Advertising value and advertising on the web. Journal of Advertising Research, 36(5), 21-35.

9. Ehrenberg, A., Barnard, N., Kennedy, R., \& Bloom, H. (2002). Brand advertising as creative publicity. Journal of Advertising Research, 42, 7-18.

10. Hirschman, E. C., \& Holbrook, M. B. (1982). Hedonic consumption: Emerging concepts, methods and propositions. Journal of Consumer Research, 9, 132-140.

11. Hoch, S. J., \& Ha, Y. -W. (1986). Consumer learning: Advertising and the ambiguity of product experience. Journal of Consumer Research, 13 (2), 221-233. doi:10.1086/209062

12. Keller, K. L. (2008). Strategic brand management: Building, measuring, and managing brand equity (Vol 3.). New Delhi: Dorling Kindersley.

13. Leigh, J. H. \& Martin, C. R. (1990).Consumer processing of advertising.Current Issues and Research in Advertising, 198-199.

14. Machleit, K. A., Allen, C. T. \& Madden, T. J. (1993). The mature brand and brand interest: An alternative consequence of Ad-evoked affect. Journal of Marketing, 57, 72-82.

15. Markman, A. B. \& Loewenstein, J. (2010).Structural comparison and consumer choice. Journal of Consumer Psychology, 20, 126-137.

16. Marshall, A. (1920). Principle of Economics. (Vol 8.) New York: The Macmillan Company.

17. McDonald, C. (1992). How advertising works. Henley-on-Thames: The Advertising Association in association with NTC Publications Ltd.

18. McFadden, D. (1978). Modelling the Choice of Residential Location. In A. Karlgvist et al. (ed.). Spatial interaction: Theory and residential location. Amsterdam: North Holland. 
19. Onyenyili-Onuorah, J. (2005). Advertising and society: Contemporary socio-economic issues in advertising and public relations. Lagos: Raindrops Ltd.

20. Resurreccion, A. V. A. (2003). Sensory aspect of consumer choices for meat and meat products. Meat Science, 66(1), 11-20.

21. Richards, J. I., \& Curran, C. M. (2002). Oracles on "advertising”: Searching for a definition. Journal of Advertising, 31(2), 63-77.

22. Russo, J. E., \& Chaxel, A. -S. (2010). How persuasive messages can influence behavior without awareness. Journal of Consumer Psychology, 20, 338-342. doi:10.1016/j.jcps.2010.06.005

23. Senecala, S., \& Nantel, J. (2004). The influence of online product recommendations on consumers' online choices. Journal of Retailing, 80(2), 159-169. doi:10.1016/ j.jretai.2004.04.001

24. Shimp, T. A. (2007). Integrated marketing communications in advertising and promotion (Vol. 7). Mason: $\mathrm{OH}$, Thomson Higher Education.

25. Suk, K., Lee, J. \& Lichtenstein, D. R. (2012). The influence of price presentation order on consumer choice. Journal of Marketing Research, 49(5), 708-717. doi:10.1509/jmr.11.0309

26. Tellis, G. J., Chandy, R. K., \& Thaivanich, P. (2000). Which ad works, when, where, and how often? Modeling the effects of direct television advertising. Journal of Marketing Research, 37(1), 32-46.

\section{Contact information}

Olalekan Oladipo David

University of South Africa

College of Economic and Management Sciences

Department of Economics

Pretoria, South Africa

Babatunde Musiliu Abina

Al-Hikemah University

College of Management Sciences

Department of Business Administration

Ilorin, Nigeria

Ishola Wasiu Oyeniran

Al-Hikmah University

College of Management Sciences

Department of Economics

Ilorin, Nigeria 